Part of Journal of Research of the National Bureau of Standards, Volume 22, June 1939

\title{
ELECTROANALYTICAL DETERMINATION OF COPPER AND LEAD IN NITRIC ACID SOLUTION CONTAINING SMALL AMOUNTS OF HYDROCHLORIC ACID
}

\author{
By John A. Scherrer, Rosemond K. Bell, and William D. Mogerman
}

\section{ABSTRACT}

In the analysis of copper-base alloys, chiefly brasses and bronze, difficulties have been encountered in consistently obtaining quantitative depositions of copper in nitric acid solutions, unless the nitric acid solution of copper is either fumed with sulfuric acid or evaporated to dryness and baked moderately. As a result of experiments made to remedy this trouble, it has been found that complete deposition of copper is obtained if a trace of chloride ion (1 drop of $0.1 \mathrm{~N}$ hydrochloric acid) is added to the nitric acid solution either during the solution of the alloy or at the beginning of the electrolysis.

\section{CONTENTS}

I. Introduction

II. Procedure

III. Discussion

698

\section{INTRODUCTION}

Electroanalytical determinations of copper in copper-base alloys, such as brass and bronze, are usually made by depositing the metal from an electrolyte containing sulfuric and nitric acids. For example, in analyses of alloys containing moderate amounts of lead, (less than 10 percent), the alloy may be dissolved in diluted nitric acid, the solution evaporated to dryness, and baked moderately. The residue is digested with nitric acid, diluted, and the solution filtered if metastannic acid is present. The solution is then electrolyzed and, after 1.5 to 2.5 hours, when all or most of the lead has been deposited as the peroxide on the anode, 3 to $4 \mathrm{ml}$ of sulfuric acid is added, and the electrolysis continued to complete the deposition of copper on the cathode.

If larger amounts of lead are present, after tin is removed as metastannic acid, sulfuric acid is added to the nitric acid solution and the lead removed by evaporating the solution to fumes of sulfuric acid, diluting, and filtering. Three to four $\mathrm{ml}$ of nitric acid is added to the filtrate, which is then electrolyzed for copper and residual lead.

In one of the procedures used at the National Bureau of Standards for the routine analysis of brasses and bronzes, the alloy is dissolved in diluted nitric acid and the solution boiled for about 5 minutes after oxides of nitrogen are no longer visible. The solution is then diluted, neutralized with ammonium hydroxide, made about 3-percent acid with nitric acid, and electrolyzed. If tin is present, the solution is filtered before neutralizing with ammonium hydroxide. This method is shorter than those calling for dehydration, or fuming with 
sulfuric acid, and is applicable for the simultanoeus determination of copper and lead in many of the alloys which are received for analysis. This procedure had been used at the Bureau for a number of years and yielded satisfactory results for copper and lead. Recently, however, increasing difficulties were experienced in obtaining quantitative deposition of copper. For example, in a series of 10 electrolyses, run at the same time, satisfactory deposition of copper would be obtained in possibly 6 to 8 cases, and only 50 - to 80 -percent deposition in the other determinations.

Experiments were made from time to time in an attempt to find and eliminate the trouble. A number of so-called addition-agents, such as sulfur dioxide, hydrogen peroxide, urea, and a number of other organic materials, were added to the electrolyte both prior to, and during electrolysis, but none of these were satisfactory. It was observed, however, that if the nitric acid solution was evaporated to dryness and the residue baked moderately, or if the solution was fumed with sulfuric acid and nitric acid added, satisfactory deposition of copper was obtained in the subsequent electrolysis. ${ }^{1}$ Prolonged boiling of the nitric acid solution of copper, or evaporation of the solution to dryness on a steam bath, lessened the number of faulty determinations, but did not completely eliminate the difficulty of obtaining quantitative depositions.

With the thought that traces of certain elements possibly in the nitric acid of earlier date might have had a critical effect, experiments were made in which small amounts of halides were added to the nitric acid. Surprisingly, it was found that quantitative deposition of copper is obtained if a trace of chloride ion (1 drop of $0.1 \mathrm{~N}$ hydrochloric acid) is added to the nitric acid solution, either during solution of the alloy or at the beginning of the electrolysis. Deposits of copper so obtained are of normal appearance, and the attack on the electrodes is no greater than is encountered in the absence of hydrochloric acid. ${ }^{2}$

\section{PROCEDURE}

The following procedure is recommended for the routine determination of lead and copper in brasses and bronzes.

Cylindrical electrodes 1.5 and 2 inches in diameter, and 1.75 inches in height, made from approximately 50-mesh platinum gauze are the most satisfactory type. Before using the electrodes they must be thoroughly cleaned and ignited to remove any previous deposit or grease. To do this, immerse the electrodes in diluted nitric acid $(1+1)^{3}$ until copper, lead or other metals are dissolved. ${ }^{4}$ Remove the electrodes, rinse with distilled water, and place them in a fresh solution of diluted nitric acid $(1+1)$. Add a few drops of ethyl alcohol and boil for about 10 minutes. Remove, and rinse the electrodes with distilled water. Ignite in the flame of a large burner, or several burners, so that the entire gauze area is uniformly heated (to bright redness) for 5 minutes or more. Cool in a desiccator, and weigh.

\footnotetext{
${ }^{1}$ It should be mentioned that very small amounts of copper, usually less than $0.2 \mathrm{mg}$, may remain in the electrolyte.

${ }^{2}$ In an internal electrolysis method for copper and bismuth, Clark, Wooten, and Luke add a little chloride to open clogged diaphragms (Ind. Eng. Chem. Anal. Ed., 8, 411 (1936).

8 This denotes, throughout the paper, 1 volume of concentrated nitric acid ( $\mathrm{sp}$ gr 1.42) diluted with 1 volume of water. If no dilution is specified, the concentrated reagent is meant.

- With a heavy deposit of lead peroxide, add a few drops of ethyl alcohol and heat until solution ensues.
} 
Place $1 \mathrm{~g}$ of the well-mixed sample in a 250-ml beaker, cover, add $25 \mathrm{ml}$ of diluted nitric acid $(1+1)$ and 1 drop of $0.1 \mathrm{~N}$ hydrochloric acid. When the action has ceased, heat to boiling, and continue the boiling for about 5 minutes after the red oxides of nitrogen have disappeared. Dilute to about $150 \mathrm{ml}$ with distilled water. If the alloy contains tin, use hot distilled water, digest the solution for an hour or more, filter through a paper of close texture, and wash the precipitate with hot diluted nitric acid $(1+99) .^{5}$

Neutralize ${ }^{6}$ the filtrate with ammonium hydroxide, ${ }^{7}$ add an excess of $6 \mathrm{ml}$ of nitric acid, ${ }^{8}$ and dilute to $200 \mathrm{ml}$. Insert the electrodes so that the surface of the cathode clears the anode by at least $5 \mathrm{~mm}$, and both electrodes almost touch the bottom of the beaker. Cover the beaker with split watch glasses, and electrolyze with a current of 0.2 to 0.4 ampere until deposition is complete, usually overnight. Without interrupting the current, slowly lower the beaker, and, at the same time, wash the electrodes with a stream of distilled water. Immediately immerse the electrodes in another beaker containing distilled water, lower the beaker, discontinue the current, and disconnect the electrodes. Rinse the cathode with ethyl alcohol, shake off the excess alcohol, and dry for a few minutes in an oven at $110^{\circ} \mathrm{C}$. Cool in a desiccator and weigh. If a deposit of lead peroxide is indicated on the anode, rinse the latter with water and dry for about an hour at $180^{\circ} \mathrm{C}$. Cool in a desiccator, weigh as $\mathrm{PbO}_{2}$, and use the factor 0.866 to calculate the percentage of lead. ${ }^{9}$

\section{DISCUSSION}

Results obtained when the recommended procedure was applied to samples of copper and lead of high purity are shown in tables 1 and 2 . In addition, the procedure has now been in daily use for the past year in the analysis of various brasses and bronzes in the Bureau's laboratories, without a single instance of unsatisfactory deposition of copper.

The addition of the very small amount of chloride ion does not cause any significant attack on the electrodes. The loss in weight of the anodes in 75 electrolyses averaged less than $0.1 \mathrm{mg}$, which is of the same order of magnitude as in the absence of hydrochloric acid.

As regards the minimum amount of chloride ion, 5 drops of $0.01 \mathrm{~N}$ hydrochloric acid generally yielded quantitative deposition of copper, but less than this amount was not satisfactory.

Despite a considerable amount of experimental work, no suitable explanation can be offered at this time as to why the addition of a small amount of chloride ion eliminates the difficulties encountered in obtaining quantitative deposition of copper from a nitric acid solution. Hydrochloric acid had the same effect whether added during solution of the sample, or at the beginning of the electrolysis. It was also

\footnotetext{
s Slight amounts of copper and lead are retained by the metastannic acid and should be recovered in very accurate work, but they are generally disregarded in routine analyses. The recovery can be made by treat. ing the precipitate and paper with sulfuric and nitric acids until the paper is destroyed and then making an alkaline sulfide separation. The presence of the very small amount of hydrochloric acid does not vitiate the complete separation of tin as metastannic acid.

o Litmus paper is a suitable indicator, though, with a little experience, the neutral point can be located by the formation of the blue-colored copper complex in ammoniacal solution.

7 See page 700 , for procedure with $5 \mathrm{~g}$ of copper.

8 Tests have shown that when, in the absence of lead, an excess of $5 \mathrm{ml}$ of sulfuric acid is added instead of nitric acid, complete deposition of copper is obtained without the addition of hydrochloric acid.

- If manganese is present in the electrolyte some of it will be deposited with the lead. In this case dissolve the deposit in about $10 \mathrm{ml}$ of diluted nitric acid $(1+1)$ containing a few drops of ethyl alcohol. Dilute, and treat with hydrogen sulfide. Filter the lead sulfide, dissolve it in nitric acid, and deposit the lead electrolytically as the peroxide.
} 
found that if the deposition of copper in nitric acid solution was not complete in 18 hours in the old method, continued electrolysis did not help, but if 1 drop of $0.1 \mathrm{~N}$ hydrochloric acid was then added, quantitative deposition of copper was obtained within the time indicated in the recommended procedure.

TABLE 1.-Results obtained by applying the recommended procedure in analyses o high-purity copper

COPPER

\begin{tabular}{|c|c|c|c|}
\hline Added & Recovered 1 & Added & Recovered 1 \\
\cline { 1 - 2 }$g$ & $g$ & $g$ & \\
0.0580 & 0.0580 & 1.0075 & 1.0073 \\
.0570 & .0571 & 1.0052 & 1.0051 \\
.1568 & .1568 & 1.0006 & 1.0007 \\
.1505 & .1506 & 1.0005 & 1.0006 \\
1.0056 & 1.0055 & 2.0007 & 2.0008 \\
1.0056 & 1.0054 & 2.0001 & 2.0001 \\
\hline
\end{tabular}

${ }^{1}$ A little copper was usually left in the electrolyte-less than $0.1 \mathrm{mg}$ in electrolyses of 50 to $150 \mathrm{mg}$ of copper and from 0.05 to $0.2 \mathrm{mg}$ in those involving 1 to $2 \mathrm{~g}$ of copper.

TABLE 2.-Results obtained by applying the recommended procedure to mixtures of copper and lead of high purity

\begin{tabular}{|c|c||c|c|}
\hline \multicolumn{2}{|c||}{ Copper } & \multicolumn{2}{c|}{ Lead } \\
\hline Added & Recovered 1 & Added & Recovered \\
\cline { 2 - 4 } & $g$ & $g$ & $g$ \\
1.0072 & 1.0072 & 0.0562 & 0.0561 \\
1.0026 & 1.0026 & .0543 & .0539 \\
1.0073 & 1.0072 & .0636 & .0636 \\
1.0066 & 1.0065 & .0635 & .0636 \\
1.0002 & 1.0002 & .0559 & .0559 \\
1.0007 & 1.0005 & .0559 & .0555 \\
\hline
\end{tabular}

${ }^{1}$ A little copper, ranging from 0.05 to $0.2 \mathrm{mg}$, was usually left in the electrolyte.

Although the recommended procedure is not intended to replace the Battery Assay Method for Copper specified by the American Society for Testing Materials, ${ }^{10}$ the procedure is useful, in cases where sulfates are objectionable, for separating copper in large samples. However, with $5 \mathrm{~g}$ of copper, neutralization with ammonium hydroxide is not satisfactory, and the procedure is modified as follows: Dissolve $5 \mathrm{~g}$ of sample in exactly $30 \mathrm{ml}$ of diluted nitric acid $(1+1)$. Add 1 to 2 drops of $0.1 \mathrm{~N}$ hydrochloric acid, and boil gently for about 5 minutes after the red oxides of nitrogen have disappeared. Dilute to $225 \mathrm{ml}$, electrolyze with a current of 0.4 ampere until deposition is complete, usually 17 to 19 hours. Quantitative deposition is obtained. For example, in a series of eight determinations on 5-g samples, the undeposited copper in the electrolyte ranged from 0.1 to $0.3 \mathrm{mg}$.

Sodium chlorate, potassium bromide or bromate, and potassium iodide or iodate function like hydrochloric acid or sodium chloride, but the weight of the deposited copper was generally a few tenths of a milligram too high. The addition of 1 to 2 drops of $0.1 \mathrm{~N}$ hydrofluoric acid does not cause complete deposition in the absence of chloride; on the other hand, it does not vitiate the beneficial action of the chloride ion in the recommended method.

Washington, March 20, 1939.

${ }_{10}$ Methods of Chemical Analysis of Metals, ASTM, p. 111, Designation: B34-36T. (1936). If lead-and tin-free brasses are dissolved in the sulfuric-nitric acid mixture specified in the Battery Assay Method, quantitative deposition of copper will be obtained when the solution is electrolyzed. 